\title{
Computational Investigation on Anti Cancer Compounds against Aldose Reductase as Anti Diabetic Agents
}

\author{
Naresh Babu Muppalaneni \\ Associate Professor \\ Avanthi's Research \& \\ Technological Academy
}

\author{
Prof. Allam Appa Rao \\ First Vice- Chancellor \\ JNTU K, Kakinada
}

\begin{abstract}
An investigation has been carried out to find out the anti cancerous compounds can exhibit anti diabetic against aldose reductase. Diabetes and cancer are common diseases worldwide. In our study we have taken 17 anti cancerous compounds from inhouse chalcones database to perform docking studies. It reveals that there are some compounds which are binding with high affinity than the average docking score -126.048 $\mathrm{kcal} / \mathrm{mol}$ of ligands of the $1 \mathrm{AH} 3$ protein. The anti cancer compounds exhibit high docking score than the average $-126.048 \mathrm{kcal} / \mathrm{mol}$. The anti cancer compound can be used as anti diabetic.
\end{abstract}

Keywords: Bioinformatics, Docking studies, anti cancer, anti diabetic

\section{INTRODUCTION}

Diabetes and cancer are common diseases with tremendous impact on health worldwide. Epidemiologic evidence suggests that people with diabetes are at significantly higher risk for many forms of cancer. Type 2 diabetes and cancer share many risk factors, but potential biologic links between the two diseases are incompletely understood [1].

In vitro studies indicate that PPAR-gamma agonists have several anti-cancer activities, such as inhibiting growth and inducing apoptosis and cell differentiation [2], and PPAR-gamma is currently considered a potential target for both chemoprevention and cancer therapy based on other preclinical studies [3,4]. However, since recent in vitro studies indicate that the effects of PPAR-gamma agonists on cell growth are often independent of the presence of PPAR-gamma [57], the clinical relevance of findings of in vitro studies is unclear.

\section{METHODOLOGY}

17 Anti cancer compounds were available which are proved to be anticancerous. We have taken those compounds to see whether they can inhibit the Aldose Reductase enzyme.

An investigation has been carried out to study the mode of binding as well as the affinities of druglike compounds from inhouse cancer compounds as anti-diabetic agents by performing protein ligand interactions using various docking software.

In order to find the best ligand having affinity/docking score more than the average $126.048 \mathrm{kcal} / \mathrm{mol}$.

\section{RESULTS AND DISCUSSIONS}

The Mol Dock Scores of the 17 anti-cancerous compounds are shown in the Table 1 .

Table 1: Table showing the docking scores of the anticancer compounds

\begin{tabular}{|c|c|c|}
\hline S.No. & Compound & Affinity $(\mathbf{k c a l} / \mathbf{m o l})$ \\
\hline $\mathbf{1}$ & Compound 1 & -159.429 \\
\hline $\mathbf{2}$ & Compound 2 & -152.77 \\
\hline $\mathbf{3}$ & Compound 3 & -144.901 \\
\hline $\mathbf{4}$ & Compound 4 & -150.078 \\
\hline $\mathbf{5}$ & Compound 5 & -143.698 \\
\hline
\end{tabular}




\begin{tabular}{|c|c|c|}
\hline $\mathbf{6}$ & Compound 6 & -131.425 \\
\hline $\mathbf{7}$ & Compound 7 & -175.694 \\
\hline $\mathbf{8}$ & Compound 8 & -156.709 \\
\hline $\mathbf{9}$ & Compound 9 & -160.97 \\
\hline $\mathbf{1 0}$ & Compound 10 & -144.505 \\
\hline $\mathbf{1 1}$ & Compound 11 & -130.74 \\
\hline $\mathbf{1 2}$ & Compound 12 & -143.031 \\
\hline $\mathbf{1 3}$ & Compound 13 & -154.539 \\
\hline $\mathbf{1 4}$ & Compound 14 & -148.449 \\
\hline $\mathbf{1 5}$ & Compound 15 & -149.771 \\
\hline $\mathbf{1 6}$ & Compound 16 & -159.008 \\
\hline $\mathbf{1 7}$ & Compound 17 & -114.775 \\
\hline
\end{tabular}

\section{BEST COMPOUNDS:}

There were many compounds which had a dock score greater than the average dock score ($126.048 \mathrm{kcal} / \mathrm{mol}$ ) of the inhibitors taken from literature.

In each of the above section of compounds, the best top 10 compounds were taken.

\section{Best compounds from the anti-cancer compounds:}

The dock scores of the top 10 compounds out of the 17 anti cancer compounds are given in the Table 2.

Table 2: Table showing the docking scores of the best compounds from anticancer compounds.

\begin{tabular}{|c|c|r|}
\hline S.No. & Compound & $\begin{array}{c}\text { Affinity } \\
\text { (kcal/mol) }\end{array}$ \\
\hline $\mathbf{1}$ & Compound 7 & -175.694 \\
\hline $\mathbf{2}$ & Compound 9 & -160.97 \\
\hline $\mathbf{3}$ & Compound 1 & -159.429 \\
\hline $\mathbf{4}$ & Compound 16 & -159.008 \\
\hline $\mathbf{5}$ & Compound 8 & -156.709 \\
\hline $\mathbf{6}$ & Compound 13 & -154.539 \\
\hline $\mathbf{7}$ & Compound 2 & -152.77 \\
\hline $\mathbf{8}$ & Compound 4 & -150.078 \\
\hline $\mathbf{9}$ & Compound 15 & -149.771 \\
\hline $\mathbf{1 0}$ & Compound 4 & -148.449 \\
\hline
\end{tabular}

\section{Consensus Scoring:}

As scoring functions are derived from X-ray structures, only the favorable interactions are rewarded but unfavorable interactions are not penalized because information from the crystal structures cannot be obtained. Uncertainties in the protonation states and the involvement of water in ligand binding complicate scoring. Such cases can be overcome by using consensusscoring schemes, which are able to describe the main characteristics of protein-ligand binding [8]

Consensus scoring is a widely used approach to improve the scoring reliability and hit rate in virtual screening. As more scoring functions are introduced, a wise selection of the most appropriate scoring functions for a specific problem and a combination of these scoring functions have been shown to outperform one single scoring function $[9,10]$. Consensus scoring combines information from different scores to balance errors in single scores and improve the probability of identifying 'true' ligands [11]

Molegro Virtual Docker was used to dock compounds to generate an ensemble of docked conformations and each scoring function is applied to generate classes based on the obtained dock scores followed by ranking the best conformations. During ranking, signs of some scoring functions are changed to make certain that a lower score always indicates a higher affinity

\section{Rank-Sum Technique:}

Ranking was done individually by clustering best scored compounds into equally split four classes using Tsar software, of which compounds in Class4 represents the highest class or top rank. Classes were generated for all scoring functions and instead of taking an average, rank-sum technique[10] was employed to retrieve best compounds. The ranks obtained from each of the individual scoring functions were added to give a rank-sum. The advantage of a sum over an average is that the contribution from each individual score can more easily be split out for illustrative purposes in the former instance.

The docking scores of the above best compounds in the six different software, the classes generated using Tsar software and the sum of the classes for each ligand are shown in Table $3 \& 4$ (Annexure1) 
Further filtering of the best compounds:

Further filtering of the top 10 compounds from each section through consensus scoring and ranksum technique resulted in the following compound.

Anticancer compounds: Compound 16<smiles>Cc1ccccc1Cn1cc(NC(=O)c2cnn3c(C(F)F)cc(-c4ccccc4)nc23)cn1</smiles>

Figure 1: Structure for In house Compound 16

\section{CONCLUSION}

Screening methods are routinely and extensively used to reduce cost and time of drug discovery. Analysis was conducted using different docking programs and the molecules drawn in ISIS Draw software are energy minimized using cosmic optimize 3D module of Tsar (Tools for structure activity relationships) software. It has been clearly shown that the approach used in this study is successful in finding new inhibitors which are anti cancer. Compound16, in particular, from inhouse chalcone database showed high binding affinity against Aldose reductase, 1AH3. The docked pose of the compound exactly fits into the active site region and the ligand formed more number of $\mathrm{H}$-bond interactions than the cocrystallized ligand. The anti cancer compounds exhibit high docking score than the average $126.048 \mathrm{kcal} / \mathrm{mol}$. The anti cancer compound can be used as anti diabetic.

\section{REFERENCES}

[1] Edward Giovannucci Et Al, Diabetes Care, Volume 33, Number 7, July 2010

[2] Ohta K, Endo T, Haraguchi K, Hershman JM, Onaya T. Ligands for peroxisome proliferator-activated receptor gamma inhibit growth and induce apoptosis of human papillary thyroid carcinoma cells. J Clin Endocrinol Metab 2001;86:2170-2177

[3] Panigrahy D, Huang S, Kieran MW,Kaipainen A. PPAR gamma as a therapeutic target for tumor angiogenesis and metastasis. Cancer Biol Ther 2005;4: 687-693

[4] Ondrey F. Peroxisome proliferator-activated receptor gamma pathway targeting in carcinogenesis: implications for chemoprevention. Clin Cancer Res 2009; $15: 2-8$

[5] Clay CE, Namen AM, Atsumi G, Trimboli AJ, Fonteh AN, High KP, Chilton FH. Magnitude of peroxisome proliferatoractivated receptor-gamma activation is associated with important and seemingly opposite biological responses in breast cancer cells. J Investig Med 2001; 49:413420

[6] Clay CE, Monjazeb A, Thorburn J, Chilton FH, High KP. 15-Deoxy-delta12,14prostaglandin J2-induced apoptosis does not require PPAR gamma in breast cancer cells. J Lipid Res 2002;43: 1818-1828

[7] Palakurthi SS, Aktas H, Grubissich LM, Mortensen RM, Halperin JA. Anticancer effects of thiazolidinediones are independent of peroxisome proliferator-activated receptor gamma and mediated by inhibition of translation initiation. Cancer Res 2001;61:6213-6218

[8] Kitchen DB, Decornez H, Furr JR, Bajorath $\mathrm{J}$ (2004). "Docking and scoring in virtual screening for drug discovery: methods and applications". Nature reviews. Drug discovery 3 (11): 935-49. doi:10.1038/nrd1549. PMID 15520816

[9] Wang R, Y Lu, S Wang 2003 Comparative evaluation of 11 scoring functions for molecular docking. J Med Chem 46:22872303.

[10] Clark RD, A Strizhev, JM Leonard, JF Blake, JB Matthew 2002 Consensus scoring 
for ligand/protein interactions. J Mol Graph Model 20:281-295.

[11] Charifson PS, JJ Corkery, MA Murcko, WP Walters 1999 Consensus scoring: A method for obtaining improved hit rates from docking databases of three-dimensional structures into proteins. J Med Chem 42:5100-5109.

\section{AUTHOR PROFILES:}

Mr. M Naresh Babu is a doctoral student of Prof Allam Appa Rao, who is working on investigation of anti diabetic agents using bioinformatic tools. He obtained his graduation, post graduation of Andhra University. He published about 8 research papers in the area of bioinformatics. Currently he is working as Associate Professor and Head of the department of Computer Science \& Engineering in Avanthi's Research \& Technological Academy.

Dr Allam Appa Rao was the first Computer Engineering scholar from Andhra University to receive Ph.D in Computer Engineering in the year 1984.

19 scholars were awarded $\mathrm{Ph}$. $\mathrm{D}$ degrees under his tutelage and another 12 have submitted their $\mathrm{PhD}$ theses. "Best Academician Award" and "Best Researcher Award" were bestowed on him by Andhra University. Andhra Pradesh Government accorded him "Best Teacher" award. Dr Allam proposed new computing methods, and showed the way to better treatments of disease and better understanding of healthy life. Perhaps even more intriguing, his work may enable the design of entirely novel systems that could prove useful in applications ranging from medicines to environmental cleanup and more.

\section{ANNEXURE-1}

Table 3: Scores of the top 10 anticancer compounds obtained from different docking softwares.

\begin{tabular}{|c|l|r|r|r|r|r|r|}
\hline S.No. & \multicolumn{1}{|c|}{ Compound } & $\begin{array}{c}\text { Molegro } \\
(\mathbf{k c a l} / \mathbf{m o l})\end{array}$ & $\begin{array}{c}\text { Ehits } \\
(\mathbf{k c a l} / \mathbf{m o l})\end{array}$ & $\begin{array}{c}\text { Vina } \\
(\mathbf{k c a l} / \mathbf{m o l})\end{array}$ & $\begin{array}{c}\text { Gold } \\
(\mathbf{k c a l} / \mathbf{m o l})\end{array}$ & $\begin{array}{c}\text { MEDock } \\
(\mathbf{k c a l} / \mathbf{m o l})\end{array}$ & $\begin{array}{c}\text { Patchdock } \\
(\mathbf{k c a l} / \mathbf{m o l})\end{array}$ \\
\hline 1 & Compound 7 & -175.694 & -7.2515 & -8.4 & 76.52 & -12 & 5254 \\
\hline 2 & Compound 9 & -160.97 & -5.6382 & -8.9 & 72.03 & -27.58 & 5292 \\
\hline 3 & Compound 1 & -159.429 & -5.3184 & -9.7 & 75.16 & -10.63 & 5742 \\
\hline 4 & Compound 16 & $\mathbf{- 1 5 9 . 0 0 8}$ & $\mathbf{- 9 . 1 9 4 2}$ & $-\mathbf{1 0 . 6}$ & $\mathbf{8 3 . 0 2}$ & $-\mathbf{1 1 . 1 7}$ & $\mathbf{5 7 4 0}$ \\
\hline 5 & Compound 8 & -156.709 & -5.8169 & -8.6 & 79.82 & -10.05 & 5256 \\
\hline 6 & Compound 13 & -154.539 & -5.3923 & -10.8 & 58.29 & -10.67 & 5544 \\
\hline 7 & Compound 2 & -152.77 & -5.5272 & 9.3 & 78.81 & -11.16 & 5626 \\
\hline 8 & Compound 4 & -150.078 & -6.5669 & -9.4 & 63.56 & -10.67 & 5776 \\
\hline 9 & Compound 15 & -149.771 & -5.6498 & -10.1 & 79.75 & -12.07 & 5324 \\
\hline 10 & Compound 14 & -148.449 & -0.3819 & -7.6 & 41.25 & -10.7 & 5314 \\
\hline
\end{tabular}

Table 4: Classes generated using Tsar software.

\begin{tabular}{|c|l|r|r|r|r|r|r|r|}
\hline S.No. & \multicolumn{1}{|c|}{ Compound } & \multicolumn{1}{c|}{ Molegro } & \multicolumn{1}{c|}{ Ehits } & \multicolumn{1}{c|}{ Vina } & \multicolumn{1}{c|}{ Gold } & \multicolumn{1}{c|}{ MEDock } & \multicolumn{1}{l|}{ Patchdock } & \multicolumn{1}{l|}{ Sum } \\
\hline 1 & Compound 7 & 4 & 4 & 2 & 4 & 1 & 1 & 16 \\
\hline 2 & Compound 9 & 2 & 3 & 2 & 3 & 4 & 1 & 15 \\
\hline 3 & Compound 1 & 2 & 3 & 3 & 4 & 1 & 4 & 17 \\
\hline 4 & Compound 16 & 2 & 4 & 4 & 4 & 1 & 4 & 19 \\
\hline 5 & Compound 8 & 2 & 3 & 2 & 4 & 1 & 1 & 13 \\
\hline $\mathbf{6}$ & Compound 13 & 1 & 3 & 4 & 2 & 1 & 3 & 14 \\
\hline 7 & Compound 2 & 1 & 3 & 3 & 4 & 1 & 3 & 15 \\
\hline 8 & Compound 4 & 1 & 3 & 3 & 3 & & 4 & 15 \\
\hline
\end{tabular}


International Journal of Computer Applications (0975 - 8887)

Volume 31-No.2, October 2011

\begin{tabular}{|c|l|r|r|r|r|r|r|r|}
\hline 9 & Compound 15 & 1 & 3 & 4 & 4 & 1 & & 1 \\
\hline 10 & Compound 14 & 1 & 1 & 1 & 1 & 1 & 1 & 6 \\
\hline
\end{tabular}

